daylight are crimson, pink, or purple in gas or electric light. During the War, blue lamp bulbs were needed, but they had to appear blue when illuminated by the glow of a red filament. Had absorption spectra of colouring oxides been available, much money and labour spent in fruitless experiments would have been saved.

It was due to the measurements made by physicists on the indices of refraction of small crystals that the two crystalline forms of silica were detected, and the knowledge of the transformations has placed the whole manufacture of silica bricks on a sound scientific foundation. Recent work on X-ray spectra promises shortly to do. for the fire-brick manufacturer what a knowledge of indices of refraction has done for the silica-brick manufacture.

Applications of magnetism have been but partially explored. One problem that has been almost solved is the separation of particles of metallic iron from clay slip. A system of electromagnets made by the Rapid Magnetting Company is ingeniously arranged so that if the magnets cease to work, the dirty slip will not pass into the purified slip. Success, however, has not yet been attained in removing particles of cupriferous pyrites from fire-clays.

The physicist-engineer specialising in heat problems has an illimitable field for his knowledge and skill. Dr. Mellor estimates that in firing biscuit-ware only 2 per cent. of the fuel is usefully employed, although the processes of brick-firing are much more efficient. Another series of problems awaiting solution is connected with the drying of clays and clay-ware, where serious losses occur owing to the development of drying cracks unless an inordinately long time is allowed. It appears that little progress is possible until the physicist has worked out the distribution of water in the interior of a drying mass of clay, and he will obviously have to take into account the relation between the surface of the drying solid and the humidity of the surrounding atmosphere.

Dr. Mellor referred to the studies of the thermal strains in "ideal" kilns upon which Prof. Lees is engaged; later it is hoped to apply these results to actual kilns, and he expressed the wish that Prof. Lees would pass on to consider contraction strains set up during the uneven drying and firing of special shapes. The results of such an investigation will not only explain why some shapes fracture and others do not, but they will also indicate to the designer of chemical and sanitary apparatus, furnaces and coke ovens, the shapes to be avoided on account of the narrow margin of safety in manufacture and use. Numerous interesting problems relating to the grain of clay await solution. It appears, for example, that the particles can be oriented differently so that the drying and firing contractions are different in different directions. Then there is the plasticity of clays to be studied, and, indeed, the whole problem of the hydrostatics and dynamics of liquids with an indefinitely large number of particles in suspension. Akin to this are the colloidal problems-now ever with us-but for some unaccountable reason, which he ascribed to chance, Dr. Mellor preferred to label this branch of his subject as chemistry and not physics.

Electricity is usefully employed in high temperature testing work, and also for crucible furnaces, but a satisfactory electric furnace for firing pottery has not yet been evolved, and in any case the cost of power is here a paramount consideration. Dr. Mellor indicated the novel problems connected with the effects of convection currents of hot air that would have to be solved if electrically-heated furnaces or kilns came into use. The conditions are quite different from those in gas- or coal-fired furnaces.
In conclusion Dr. Mellor referred to the physical problems connected with the glazing of pottery. The governing condition here is that the thermal expansion of glaze and body should be the same. Data so far obtained have not taken sufficiently into consideration the complex adjustment of glaze and body; for example, there is the tensile strength of the glaze to be considered, as well as the rate at which the glaze attacks the body and the effect of solution of the body in the glaze and its coefficient of expansion.

The lecturer's statement of the case for much closer co-operation between the ceramist and the physicist than has hitherto obtained was forcible and convincing.

\section{The Meteorology of Scott's Last Journey.}

THE Halley lecture for 1923 was delivered at Oxford on May I7 by Dr. G. C. Simpson, the director of the Meteorological Office, who took for the subject of his lecture "The Meteorology of Scott's Last March."

The polar party left Hut Point on November 3 , I 9 II, and first traversed the Barrier, where it experienced a remarkable daily variation of temperature. In spite of the fact that the sun was continually above the horizon, varying only from $10^{\circ}$ above the southern horizon at midnight to about $30^{\circ}$ above the northern horizon at mid-day, the regular daily temperature variation on cloudless days reached the enormous value of $20^{\circ} \mathrm{F}$. This necessitated travelling by night and resting by day. Several serious blizzards were encountered.

It is now clear that the Barrier blizzard is extremely local, being confined to the western half of the Barrier. During ten months with simultaneous observation at Framheim-Amundsen's winter quarters in the east-and at Cape Evans in the west, winds of more than thirty miles an hour occurred during 30 per cent. of the time at Cape Evans, and only 2 per cent. at Framheim. This is due to the fact that when the pressure is higher over the Barrier than over the Ross Sea the air tends to flow from the Barrier northwards to the sea, but is deflected to the west by the earth's rotation. The edge of the western plateau extends like a wall 8000 feet high for more than a thousand miles along the west of the Barrier and of the Ross Sea. This prevents the air moving freely to the west, with the consequence that the air-flow from the whole of the Barrier is concentrated in the west, and moves northward with high velocity, giving rise to the familiar blizzard.

When the polar party was at the foot of the Beardmore Glacier it experienced a serious blizzard which gave the greatest snowfall ever recorded in high southern latitudes. The cause of this bad weather was the formation of a deep depression over the Ross Sea, which produced a great flow of warm air from the Ross Sea to the south of the Barrier.

On reaching the plateau, low temperatures were experienced. During the five weeks that Scott and his party were on the plateau the mean temperature was $-19^{\circ} \mathrm{F}$., with a maximum of $-3^{\circ} \mathrm{F}$., and a minimum of $-30^{\circ} \mathrm{F}$. As they descended from the plateau, the temperature at first rose in the normal way, but while the party was still on the glacier a great change in the weather occurred. From this date-February I I-until March 20, extremely abnormal conditions were experienced. There was little or no wind, the temperature fell rapidly to the neighbourhood of $-40^{\circ} \mathrm{F}$., and ice crystals were deposited from the cold air upon the surface which acted like sand on the runners of the sledge. These thirty-nine days were the deciding factor in the fate

No. 2796 , VOL. $x 11]$ 
of the party. " We all associate Scott's disaster with the terrible Barrier blizzards, and in the end a blizzard did prove fatal, but at this time a blizzard, a succession of blizzards would have been the salvation of them all."

The temperatures experienced by Scott on the south of the Barrier were between $10^{\circ}$ and $20^{\circ} \mathrm{F}$. below the normal for the time of year. In these conditions the returning party struggled on, becoming weaker and more dispirited every day. On March 16 , Oates made his heroic sacrifice in order to give his companions a chance of safety. Then at last-on March 20-the blizzard did come. But it came too late, and continued too long. When it commenced the party had food and fuel enough to reach the depôt at One Ton Camp only eleven miles away, but as the blizzard continued to rage day after day the fuel was used and food consumed.

"There is little doubt that this blizzard removed the cold stagnant air and the conditions over the Barrier became much better for sledge travelling. But it was too late; by the time the blizzard ceased, every man of the polar party had passed away, and in doing so had left a record and created a tradition of which every Englishman is, and always will be, proud."

\section{Movements of the Earth's Crust.}

PROF. HANS STILLE of Göttingen has issued, under the title of "Die Schrumpfung der Erde" (Berlin : Borntraeger ; price Is. 8d.), a "Festrede" given to his university, in which he aptly reviews old and new theories as to the effect of the earth's contraction on the features of the surface. He holds that the conception of a general contraction towards the interior is well founded; but there are many ways in which it may become manifest by wrinklings of the outer crust. He finds that what G. K. Gilbert styled "epeirogenic" (now written "epirogenetic") movements, the sinking or uplifting of the crust over wide areas, are more in need of explanation than the folding of mountain-ranges, which has been differentiated as " orogenetic." The rhythmic pulsation, however, that causes mountain-building to occur simultaneously and even catastrophically over the whole earth presents an unsolved problem. Prof. J. Joly has suggested in a recent lecture (NATURE, May 5, p. 603) that the heat generated by radioactive minerals accumulates at intervals of some millions of years and so causes a catastrophe. Cooling of the uplifted layers by their being brought into proximity with the overlying oceans starts a new era of quiescence.

We may ask, with an equal sense of adventurous speculation, if the pulsation may not be still more primordial and connected with the beating of the last heart of an undivided universe. Prof. Stille keeps us from any such rash imagining; but he points out that the facts of orogenetic episodes are opposed to the uniformitarian doctrines of von Hoff and Lyell, which are applicable only to the intervals between great crustal foldings. Epirogenetic movements occur during these intervals, and characterise the epoch in which we live. On the whole, the earth loses heat by radiation faster than it acquires it by contraction; in this remark we recognise an adherence to views that some geologists regard as quite oldfashioned.

Prof: Stille's ten pages of "Anmerkungen "are almost as readable as the text of the pamphlet, since he adds to a wide range of references critical observations on many of the opinions cited. He remarks that Wegener's epochs of continental drift do not coincide with those in which orogenetic movements actually occurred. In these notes the author writes, as others have lately done, "Thetys" for Suess's well-chosen name "Tēthys," possibly by a confusion of Thetis, daughter of Nereus; with the wife of Okeanos, lord of the great outer seas. A. Sander's review of diastrophism and earth-history (Geol. Rundschau, vol. I3, p. 217 , November 1922) should be read in connexion with Stille's memoir. Its author concludes similarly in favour of the contraction-theory, but regards epirogenetic movements as not necessarily very slow. Like Stille, he points out that we are moving a little way back to the views of the catastrophists.

\section{The Steel Works of Hadfields, Ltd.}

\section{Visit of H.R.H. The PRince of Wales.}

$\mathrm{M} \mathrm{UCH}$ scientific interest is attached to the visit paid by H.R.H. The Prince of Wales to the works of Messrs. Hadfields at Sheffield, on May 29, when he started up the new 28 -in. rolling mill, which has been installed at the firm's East Hecla works. This marks an important phase in the transition from war to peace production of this great establishment, the head of which is Sir Robert Hadfield, whose discovery of manganese steel in I 882 may justly be said to have originated the development of modern alloy steels. The new reversing 28 -in. blooming and finishing mill is unique in several respects, having been designed to deal satisfactorily with steels of special nature, and in particular it is equipped with all the necessary improvements and labour-saving devices to obtain the most economical production. The mill motor has a maximum rating of II,600 horse-power, and is supplied with current from a fly-wheel motor generator set, the cast-steel fly-wheel of which is II ft. 6 in. in diameter and 30 tons in weight. The mill motor is capable of being reversed from full speed in one direction to full speed in the other direction in three or four seconds. The rolls are $28 \mathrm{in}$. in diameter, and from $6 \mathrm{ft}$. 6 in. to $7 \mathrm{ft}$. long, being manufactured by Messrs. Hadfields of their special forged steel, and the mill is capable of rolling r 5 -in. square ingots, weighing $25 \mathrm{cwt}$., and reducing them to $2 \frac{1}{2}$-in. square billets at one heat. It will also be used for rolling special alloy steels, and rails up to their heaviest sections and $55 \mathrm{ft}$. long in manganese steel. The rolling plant accessories are all of the most modern type, including the necessary appliances for special treatment of manganese steel. The whole works show that British engineering is quite capable of designing, manufacturing, and running rolling mills and other steel plants second to none in the world. In addition to the 28 -in. mill, the rolling plant also includes $\mathrm{I} r$-in. and $\mathrm{I} 4$-in. mills for rolling round and square bars of alloy and other special steels.

An interesting feature of the Prince of Wales's visit was that he cast his own portrait on a plaque or medallion 22 in. in diameter of Hadfield manganese steel. The medallion was designed by Mr. S. Nicholson Babb, who has several sculptures in this year's exhibition of the Royal Academy. In the course of his tour the Prince was shown a number of exhibits illustrating the scientific work of the Hadfield Research Department. These included a complete equipment for all branches of the mechanical testing of iron and steel, and the latest apparatus in use for iron, steel, and fuel analysis, and oil testing. The scientific instruments used in the exact control of the heat treatment of special steels were also shown, and it is of interest to note that at one time no less than $x_{5}$,0oo pyrometer readings per week were taken in the works in the various steel making and treating departments. A demonstration was NO. 2796 , VOL. I I I] 